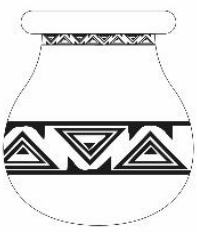

\title{
A CRÍTICA DE SCHOPENHAUER AO FORMALISMO E À NATUREZA PRESCRITIVA DA MORAL KANTIANA
}

\author{
Matheus Colares do Nascimento ${ }^{1}$
}

Resumo: O objetivo proposto pelo presente trabalho é o de expor a crítica elaborada por Schopenhauer à moral kantiana, em especial, na medida em que ela se volta para os conceitos de vontade-livre e imperativo categórico. Com efeito, Schopenhauer (1788-1860) reconhece os méritos de Kant (1724-1804) não só no âmbito da epistemologia, como também na ética, por tê-la desvinculado de todo eudaimonismo. Porém, ele ainda assim direciona-lhe algumas críticas com enfoque em questões como o formalismo da ética kantiana e o seu caráter dietético, i. e., prescritivo, que aqueles conceitos lhe adicionam.

Palavras-chave: Schopenhauer, Kant, moral kantiana, crítica ao formalismo, caráter prescritivo

\footnotetext{
${ }^{1}$ Graduado em Filosofia pela Universidade Federal do Pará (UFPA).
} 
O objetivo deste trabalho consiste na tentativa de esclarecer a crítica schopenhaueriana à filosofia moral de Kant. Faremos isso a partir da questão do formalismo e da ética prescritiva, (normativa ou dietética) presente na doutrina kantiana, de acordo com Schopenhauer. Concentrar-nos-emos, em especial, nos comentários direcionados aos conceitos de imperativo categórico e vontade-livre. Faremos primeiramente uma consideração a respeito da crítica dirigida por Schopenhauer à maneira segundo a qual tratou Kant deste segundo conceito, incluindo a possibilidade de a vontade tornar-se livre. Então passaremos a tratar da crítica schopenhaueriana à questão da possibilidade do imperativo categórico.

Segundo Schopenhauer, Kant teria sido digno de mérito ao ter feito progredir a filosofia por meio da crítica à falta de aplicabilidade epistemológica dos sistemas metafísicos anteriores a ele. Isto é, o fato de estes grandes construtos da dogmática metafísica não poderem sustentar-se em absoluto ao serem contrapostos à experiência. Em relação a isto afirma Safranski (2011, p. 200):

Kant efetivamente encontrou algumas destas 'Certezas anteriores a qualquer Experiência' (GewißheitenvorallerErfahrung), mas demonstrou igualmente que estas valem exclusivamente para a experiência [...] Esta foi a declaração solene com que fez com que os 'a prioris' descessem dos céus; a partir de então, o pensamento apriorístico deixa de servir como uma ancoragem vertical e passa a nos proporcionar somente uma orientação horizontal.

Contudo, Schopenhauer afirma ainda que o próprio Kant não teria conseguido livrar-se deste aspecto da metafísica tradicional ao tratar das questões éticas.

Ora, Schopenhauer estava ciente das frequentes contestações direcionadas à filosofia por parte das ciências naturais e, ipso facto, da impossibilidade de construção de um sistema teórico auto-referencial e apriorístico a partir de conceitos absolutos. Nesse contexto, tornavase necessário propor uma reconsideração da filosofia moral kantiana. Schopenhauer procura dar enfoque ao fato de que Kant não teria conseguido deixar de utilizar conceitos independentes da experiência (uma prática que ele mesmo propusera não mais adotar ao tratar de questões relacionadas à filosofia teórica) contrapondo-se a filósofos anteriores. Este aspecto formal da moral kantiana é objeto de crítica por parte de Schopenhauer, que corresponde ao que ele chama de formalismo da moral kantiana. Outro ponto de crítica da parte do filósofo de Leipzig é o caráter prescritivo ou normativo que Kant adota ao introduzir no seu sistema o conceito de imperativo categórico. Uma vez que, para Schopenhauer:

A filosofia nada mais pode fazer senão interpretar e explicitar o existente[...][e, portanto][...]de ética não se devem esperar prescrições nem doutrinas do dever, muito menos o estabelecimento de um princípio moral absoluto parecido a uma receita universal para a produção de todas as virtudes. (Ibid., p. 354) 
A concepção schopenhaueriana de ética vai fundamentalmente de encontro com a kantiana uma vez que ele renega a possibilidade de uma ética prescritiva e antecipatória, isto é, aquela que propõe um dever postulado de maneira a priori. Schopenhauer já no-lo mostra ao questionar em sua obra Sobre o Fundamento da Moral a doutrina kantiana: “O que vos dá o direito antecipá-lo [aquilo que deve acontecer] e logo impor uma ética na forma legislativoimperativa como a única para nós possível?” (SCHOPENHAUER, 2001, p. 23).

Para que possamos entender a crítica de Schopenhauer à moral kantiana é necessário esboçar os passos argumentativos de Kant mobilizados em favor da prescrição do dever a partir do problema da liberdade.

Para Kant, a questão da liberdade é apresentada de maneira problemática no âmbito da filosofia teórica, uma vez que fenômenos fazem parte de cadeias causais e que nada poderia encontrar-se fora do domínio delas, i. e., o da determinação, tal como afirma: "A liberdade transcendental[...] opõe-se à lei causal e uma tal ligação dos estados sucessivos de causas eficientes - segundo a qual não é possível nenhuma unidade da experiência[...]” (KANT, 2000,p. 295). Entretanto, continua ele, a razão é naturalmente levada a pensá-la, dada a sua natureza fisiológica que busca a totalidade do lado in antecedentia de um condicionado dado, i. e., que busca formular uma ideia caracterizada pela totalidade dos fenômenos, para a qual é necessário pensar uma tal espontaneidade que dê início a uma tal série desses fenômenos (Ibid., 2000, p.338). Este embate entre dois princípios constitui o espaço onde a argumentação da segunda antinomia tem lugar. A pergunta fundamental que daí advêm é a seguinte: como poder-se-ia conciliar estas duas proposições aparentemente contraditórias?

Segundo Kant, encontraríamos apenas na natureza humana um acordo entre estes dois princípios. Isto é concluído, uma vez que o homem é considerado, por ele, como um ser de carácter dual. O ser-humano possui, por um lado, um caráter empírico, o qual é determinado pela causalidade que age em todo o objeto da sensibilidade. Por outro, há um carácter inteligível correspondente a uma faculdade de determinar-se a si mesmo. O que nos permitiria concomitantemente encará-lo como estando fora dela. Ele afirma: “[...] ele [o homem] certamente é, de uma parte, fenômeno, mas de outra, ou seja, no que se refere a certas faculdades, um objeto puramente inteligível porque a sua ação de modo algum pode ser computada na receptividade da sensibilidade” (Ibid., 2000, p. 345).

A possibilidade de a ação possuir uma causa não empírica, porém, só poderia acontecer quando a razão age causalmente sobre a vontade natural segundo o conhecimento de uma lei. Tal lei deve se impor à vontade de maneira normativa de modo que a segunda se iguale a primeira a partir da a prescrição de um dever 


\section{REVISTA APOENA - Per. dos Dis. de Fil. da UFPA \\ Belém, 2019, V. 1, N.1.}

Dos imperativos que impomos, em tudo o que tange às questões práticas, como regras que as executam, segue-se claramente ou que esta razão possui uma causalidade ou que, pelo menos, a representamos para nós como possuindo tal causalidade. O dever expressa um tipo de necessidade e de conexão com fundamentos que não ocorre alhures com toda a natureza. (Ibid, 2000, p. 345).

Kant expressa este dever sob a forma do imperativo categórico mostrando, assim, "a relação de uma lei objetiva da razão com uma vontade que não é necessariamente determinada por isso segundo sua qualidade subjetiva" (KANT, 2009, p. 185.) Isto é, colocando uma obrigação perante a vontade imperfeita, a que é determinada por outras razões empíricas não provenientes da faculdade racional prática.

É por este meio que Kant propõe desligar qualquer elemento empírico ou recurso à experiência da discussão em relação a questões de cunho ético ou moral. Ele afirma:

[...] se a razão por si só não determina suficientemente a vontade esta está submetida ainda a condições subjetivas (certas molas propulsoras), que nem sempre concordam com as objetivas[...] se a vontade não é em si plenamente conforme à razão[...], então as ações que objetivamente são reconhecidas como necessárias, são subjetivamente contingentes, e a determinação de uma tal vontade, em conformidade com leis objetivas, é necessitação[...] (Ibid., 2009, p. 185).

Em outras palavras, caso a vontade esteja determinada por razões subjetivas, isto é, por condições empíricas, então ela encontrar-se-á numa cadeia de determinações. Isso retiraria dela o seu caráter autônomo. Nesse contexto, as ações aconteceriam somente por coação. Isso impossibilitaria que fossem consideradas universais, tampouco, consequentemente, como dotadas de valor moral. O único meio de fugir de tal determinação seria, segundo Kant, subordinar a vontade à razão sob a fórmula do imperativo categórico.

Schopenhauer, porém, rejeita a possibilidade de tal exigência. Adotando uma posição contrária a essa perspectiva, ele nega que a ética possa funcionar por meio da prescrição de regras, que frequentemente não ocorrem na efetividade. Uma vez que o imperativo categórico se apoia justamente neste tipo de concepção, Schopenhauer se mostra crítico em relação a esse conceito, afirmando ser algo de irrealizável. Ele apresenta uma alternativa realista e interpretativa da realidade, segundo a qual deve proceder a investigação ética:

Na minha opinião, contudo toda a filosofia é sempre teórica, já que lhe é sempre
essencial manter uma atitude puramente contemplativa, não importa o quão próximo
seja o objeto de investigação, e sempre inquirir, em vez de prescrever regras.
Tornar-se prática, conduzir a ação, moldar o caráter: eis aí pretensões antigas que
uma intelecção mais perspicaz fará por fim a filosofia abandoná-las
(SCHOPENHAUER, 2005, p. 353).

Com isso, Schopenhauer objetiva argumentar que a impossibilidade de corrigir o serhumano torna o método prescritivo da filosofia moral infrutífero. Logo, este deveria ser deixado de lado. Segundo ele, a filosofia moral, da mesma forma que a filosofia teórica, 
deveria dar explicações acerca do mundo, no caso, esclarecer a ação humana tal como ela acontece efetivamente.

O ponto de articulação da crítica schopenhaueriana e um aspecto importante da natureza da ética baseia-se, na verdade, no fato de que, segundo argumenta Debona (2, v.1, p.279): “[...]para Schopenhauer, a razão não chega a ser tão poderosa a ponto de dar origem e de fundamentar a moralidade". Sendo que é precisamente em tais pressupostos que a moral kantiana se sustenta. Schopenhauer afirma que a razão não pode ser mais que uma manifestação específica do fenômeno da vontade. Mesmo sendo uma faculdade exclusiva do ser humano em relação aos outros seres vivos, a razão permanece como uma qualidade docorpo, isto é, como uma qualidade de nossa natureza orgânica: "Não seria legítimo, portanto, pensar a razão fora da sua única espécie, o ser humano, sendo ilegítimo também, a conclusão de que existiriam seres racionais em abstrato e leis para eles, tomados abstratamente". (KATIA SANTOS, No 2, v.2, p.169). Logo, segundo Schopenhauer, a razão não poderia possuir a pretensão de fundamentar as ações humanas.

Apenas a vontade, isto é, o verdadeiro princípio motor de todas as coisas no mundo fenomênico; só ela possui a verdadeira e absoluta liberdade, que é a ausência de determinação e que Kant queria atribuir ao homem. Schopenhauer se utiliza da metafísica da vontade para fundamentar a sua ética e opor-se a Kant no que toca ao aspecto puramente ideal da ética deste: “[...] Schopenhauer funda sua ética na experiência e não em algo supra sensível, pois a Vontade, que é para ele o núcleo metafísico de todo o existente, não é um fundamente extramundano, mas imanente ao próprio mundo" (KATIA SANTOS, No 2, v.2, p.167). Para Schopenhauer, tudo está submetido ao princípio imanente da vontade que é anterior à racionalidade,inclusive as ações humanas. Schopenhauer, então, descarta de antemão a possibilidade da existência da liberdade individual, uma vez que ela é sempre, na sua essência, tal qual se manifesta no mundo, determinada. Ele afirma quea vontade-livre, ou a possibilidade de as pulsões serem determinadas pelas leis derivadas da razão prática, não pode ser confirmada na efetividade, uma vez que o ser-humano não pode ser em absoluto pensado como um em si mesmo, i. e., como sendo capaz de tornar-se livre de determinações. $\mathrm{O}$ filósofo, dessa maneira, nega a possibilidade do livre-arbítrio, admitindo uma perspectiva determinista.

Em suma, a tese principal da ética kantiana é que o homem é capaz de se tornar um ser livre, de ter uma vontade livre de determinações empíricas, i. e., uma vontade autônoma. Porém, seguindo o argumento da ética normativa, a única maneira de consegui-lo é acordando a sua própria vontade a uma lei universal a um imperativo categórico, cuja fonte é a razão. 
Esta lei deve então, impor-se sobre as determinações empíricas da vontade individual nas ações. Schopenhauer, entretanto, estava convicto de que a edificação de sistemas prescritivos que visem moldar a essência das ações humanas é um esforço infrutífero, pois, a coerência lógica de um fundamento e a reflexão normativa a priori acerca da moral não seriam suficientes para dar conta da investigação filosófica neste âmbito. Ele se propõe, então, refutar a fundamentação da moral kantiana a partir da perspectiva de sua metafísica imanente da Vontade defendendo a submissão da vontade humana à lei da causalidade e, consequentemente, a impossibilidade do imperativo categórico. Pois, para ele, uma ética prescritiva seria uma atitude de afastamento da natureza da investigação filosófica a qual deveria adotar um método que visasse esclarecer o que é dado na experiência.

\section{REFERÊNCIAS BIBLIOGRÁFICAS}

BITTENCOURT, R. N. Schopenhauer, Nietzsche e a Crítica ao Formalismo da Moral Kantiana. Rio de Janeiro,Revista Voluntas: Estudos sobre Schopenhauer, v. 2, n. 1, $1^{\circ}$ semestre de 2011, pp. 03-21.

DEBONA, V. Schopenhauer e a Razão Prática. São Paulo,Kinesis, v. 1, n. 2, p. 277-286, Outubro, 2009.

KANT, I. Fundamentação da Metafísica dos Costumes. Trad. De Guido Antônio de Almeida. São Paulo: Discurso Editorial: Barcarolla, 2009. (Coleção Philosophia).

. Crítica da Razão pura. Trad. deValerioRohden e UdoBaldurMoosburger. São Paulo: Editora Nova Cultural, 2000. (Coleção Os Pensadores)

. Kritik der reinenVernunft. Hamburg: Meiner, 1998 (PhilosophischeBibliothek).

MARTINEZ, H. L. A Recusa de Schopenhauer ao "Livre-Arbítrio" da Moral Kantiana. Curitiba, Revista de Filosofia (PUCPR), v. 18, n. 21, $2^{\circ}$ semestre de 2005, p. 45-68.

SAFRANSKI, Rüdiger. Schopenhauer e Os Anos mais selvagens da Filosofia. $1^{\text {a }}$ edição. Trad de Wiliam LagosSão Paulo: Geração Editorial, 2011.

SANTOS, K. A Razão Prática Schopenhaueriana e a Ação por Máximas. Rio de Janeiro,Revista Voluntas: Estudos sobre Schopenhauer, v. 2, n. 2, $2^{\circ}$ semestre de 2011, pp. $160-184$.

SCHOPENHAUER, A. O Mundo como Vontade e Representação. Trad. de Jair Barboza. São Paulo: Editora UNESP, 2005.

. Sobre o Fundamento da Moral. $2^{\mathrm{a}}$ edição. Trad. de Maria Lúcia

Mello Oliveira Cacciola. São Paulo: Martins Fontes, 2001. (Coleção clássicos) 
REVISTA APOENA - Per. dos Dis. de Fil. da UFPA

Belém, 2019, V. 1, N.1.

DUDLEY, W. Kant: Idealismo Transcendental. In: DUDLEY, W. Idealismo alemão. Trad. de Jacques A. Wainberg. Petrópolis: Vozes, 2013. p. 27-75. 